\title{
An interfacial uptake mechanism for the degradation of pyrene by a Rhodococcus strain
}

\author{
Murielle Bouchez, ${ }^{1,2}+$ Denis Blanchet ${ }^{1}$ and Jean-Paul Vandecasteele ${ }^{1}$
}

Author for correspondence: Murielle Bouchez. Tel: +331699351 40. Fax: +33169935084.

1 Institut Français du Pétrole, Division Chimie appliquée, Biotechnologie et Matériaux, BP 311 , 92506 Rueil-Malmaison Cedex, France

2 Commissariat à l'Energie Atomique, Centre de Cadarache, Direction du Cycle du Combustible, Département d'Entreposage et de Stockage des Déchets, 13108 Saint-Paul lez Durance Cedex, France
The mechanism of uptake of polycyclic aromatic hydrocarbons (PAHs) was studied using a kinetic approach by electrolytic respirometry. In the case of the degradation of pyrene dissolved in a non-water-soluble non-degradable solvent $(2,2,4,4,6,8,8$-heptamethylnonane), by a Rhodococcus sp., two successive phases of exponential growth, during which over $80 \%$ of substrate degradation took place, were clearly characterized. During the second phase of biodegradation, rates of pyrene uptake were higher than those determined in abiotic conditions for the physicochemical transfer of pyrene from the solvent to the aqueous phase and no evidence for the presence of glycolipidic biosurfactants was obtained. The value of the specific growth rate for the first phase $\left(\mu_{\max }\right)$ was independent of the volume of the solvent phase and of the concentration of pyrene and was, in all cases, higher than that for the second phase $\left(\mu_{\mathrm{i}}\right)$. The $\mu_{\mathrm{i}}$ values increased with the volume of the solvent phase but were independent of pyrene concentration, a clear indication of an interfacial uptake mechanism. The experimental kinetic data fitted well with a mathematical model incorporating PAH uptake both from the interface and from the aqueous medium by a population consisting of adsorbed cells in dynamic equilibrium with the cells in the aqueous medium, interfacial uptake being predominant in these experiments. Similar results were obtained for the degradation of fluoranthene. This newly demonstrated mechanism of PAH uptake is of great significance for the degradation of higher PAHs.

Keywords: electrolytic respirometry, interfacial uptake, polycyclic aromatic hydrocarbons, insoluble substrate, transfer mechanism

\section{INTRODUCTION}

The mechanisms involved in the uptake of hydrophobic compounds by micro-organisms are a key aspect of the degradation of these molecules and have been mainly studied in the case of long-chain alkanes. Although present knowledge of these mechanisms is in some respects still sketchy, there is a wide agreement on the existence of three models of alkane uptake (Goswami \& Singh, 1991; Haferburg et al., 1986; Hommel, 1994; Nakahara et al., 1977): (1) after dissolution in the aqueous phase; (2) through direct contact of the microorganisms with the hydrophobic phase-aqueous phase interface (interfacial uptake); (3) as microemulsions

†Present address: Ecole Nationale Supérieure des Industries Agroalimentaires, Laboratoire de Microbiologie Industrielle, 91305 Massy Cedex, France.

Abbreviations: $H M N, 2,2,4,4,6,8,8$-heptamethylnonane; MSM, mineral salt medium; PAH, polycyclic aromatic hydrocarbon. promoted by the production of biosurfactants. Polycyclic aromatic hydrocarbons (PAHs) are a class of hydrophobic compounds of environmental concern because of their genotoxicity, ubiquitous presence and persistence. Their biodegradation is a subject of active research (Cerniglia, 1992, 1993; Wilson \& Jones, 1993). Because the persistence of PAHs appears to be related to their low solubility and poor availability to degrading micro-organisms, the mechanisms of PAH transfer are an important point of interest (Luthy et al., 1994), but knowledge of them is limited.

We devised a kinetic approach and a methodology to characterize uptake mechanisms of poorly degradable substrates and applied it to the biodegradation of PAHs. This approach (Bouchez, 1995) involves (1) the utilization of a biphasic culture medium with the PAH dissolved in a non-water-soluble, non-degradable solvent, (2) the determination of physicochemical phasetransfer rates, (3) the continuous determination of biodegradation rates by electrolytic respirometry, and 
(4) the interpretation of the kinetic data in terms of mathematical models of uptake mechanisms. In the case of the degradation of phenanthrene [solubility $1.5 \mathrm{mg} \mathrm{l}^{-1}$ as the mean of values published by Davies \& Evans (1964), May et al. (1978) and Stucki \& Alexander (1987)] by a Pseudomonas sp., this approach unambiguously demonstrated the exclusive occurrence of the mechanism of substrate transfer to the aqueous phase in the conditions used (Bouchez et al., 1995c). In the present study, the same approach was used to investigate the uptake of higher PAHs with a much lower solubility. The results obtained during the degradation of pyrene (solubility $0.16 \mathrm{mg} \mathrm{l}^{-1}$ according to May et al., 1978) by a Rhodococcus sp., which show the existence of a different substrate uptake mechanism, are presented below.

\section{METHODS}

Chemicals. HPLC-grade acetonitrile was from SDS (Peypin, France), PAHs from Fluka and 2,2,4,4,6,8,8-heptamethylnonane (HMN) from Aldrich.

Strains. A series of bacterial strains, previously isolated (Bouchez et al., 1995b) from soils polluted or not by coal tar for their capacities to use as sole carbon and energy source a three- or four-ring $\mathrm{PAH}$, were used: Pseudomonas sp. SPheNa1 on phenanthrene, Rhodococcus sp. SFltNa1 on fluoranthene and Rbodococcus sp. SPyrNa1 on pyrene. They were maintained in a vitamin-supplemented mineral salt medium (MSM) with their isolation PAH.

Kinetics of oxygen consumption. Time courses of oxygen consumed during growth on $\mathrm{PAH}$ were conducted using a sensitive respirometric apparatus (D-12-S Sapromat, Voith, Heidenheim, Germany) consisting of twelve $500 \mathrm{ml}$ Erlenmeyer flasks placed in a water bath thermostatted at $30^{\circ} \mathrm{C}$. In the Sapromat culture flasks, oxygen was kept at a constant concentration by electrolytic production and its consumption quasi-continuously recorded (data acquisition every $40 \mathrm{~s}$ ); $\mathrm{CO}_{2}$ was trapped by soda lime pellets.

The culture flasks containing $237.5 \mathrm{ml}$ MSM medium ( $\mathrm{pH} 7$ ) were inoculated with $12.5 \mathrm{ml}$ of a culture grown on the $\mathrm{PAH}$ to be tested. PAHs were employed as sole carbon and energy sources and they were supplied dissolved in HMN. Oxygen consumption blanks (non-inoculated flasks with PAH and solvent, and inoculated flasks with solvent) were run simultaneously. No oxygen consumption was detected in these flasks.

PAH quantification. PAHs in the aqueous phase were quantified by high-performance liquid chromatography with UV detection at $254 \mathrm{~nm}$. Extraction and quantification were performed as previously described (Bouchez et al., 1995b).

PAHs in solvents were evaluated by direct injection $(1 \mu \mathrm{l})$ using the gas chromatographic system previously described (Bouchez et al., 1995b) and the following oven programme: $50^{\circ} \mathrm{C}$ for $5 \mathrm{~min}$, then $2^{\circ} \mathrm{C} \mathrm{m^{-1 }}$ to $260^{\circ} \mathrm{C}$ and $20 \mathrm{~min}$ at $260^{\circ} \mathrm{C}$.

\section{RESULTS}

Oxygen consumption during the degradation of pyrene by Rhodococcus sp. strain SFltNa1 was studied by electrolytic respirometry with the Sapromat apparatus.
The substrate was supplied dissolved in HMN (volume $V^{\prime}$, in l) to form a biphasic system. The initial concentration of pyrene, $S_{0}$, referred to the aqueous-phase volume $\left(V\right.$, in l), was $370 \mathrm{mg} \mathrm{l}^{-1}$. The kinetic data were obtained every $40 \mathrm{~s}$ but, for illustration, Fig. 1 shows the data summed over periods of $5 \mathrm{~h}$ and plotted versus time. As shown in this figure, the biodegradation of pyrene dissolved in HMN was reproducible and the metabolic activity was completed within $300 \mathrm{~h}$. No residual PAH was detected, either in the aqueous phase or in the solvent phase. The curves obtained were analysed in order to determine the mechanism of substrate uptake and compared to the results previously obtained in the case of phenanthrene dissolved in HMN (Bouchez et al., 1995c), also illustrated in Fig. 1. The curves corresponding to the phase-transfer-controlled models of biodegradation, presented in this figure, will be discussed below.

\section{Comparison of experimental kinetics with the model of growth on the substrate dissolved in the aqueous phase}

We have previously developed a model describing the kinetics of oxygen consumption when the biodegradation process implies substrate transfer to the aqueous phase before consumption (Bouchez et al., 1995c). The use of oxygen consumption to follow cell growth is based on the fact that oxygen consumption, substrate consumption and biomass formation were found to be proportional during growth on PAHs (Bouchez, 1995). In this model, summarized below, oxygen consumption follows successively two relationships.

When substrate availability is not limiting, exponential growth occurs and accordingly:

$\frac{\mathrm{d} O_{\mathrm{C}}}{\mathrm{d} t}=\mu_{\max } \cdot t$

where $O_{\mathrm{C}}\left(\mathrm{mg} \mathrm{l}^{-1}\right)$ is the oxygen consumed referred to $\mathrm{V}$, $\mu_{\max }$ the maximal specific growth rate of bacteria on the substrate involved $\left(\mathrm{h}^{-1}\right)$, and $t$ the time $(\mathrm{h})$.

Then, starting at the end of the exponential phase (occurring at time $t_{1}$, in $\mathrm{h}$, and oxygen consumed $\mathrm{O}_{\mathrm{C} 1}$, in $\mathrm{mg} \mathrm{l}^{-1}$ ), growth is controlled by the transfer of substrate from the solvent to the aqueous phase. The following equation, based on the law of transfer kinetics, is then verified:

$O_{\mathrm{C}}=O_{\mathrm{T}}-\left(\mathrm{O}_{\mathrm{T}}-\mathrm{O}_{\mathrm{C} 1}\right) \cdot \mathrm{e}^{-k_{2} \cdot\left(t-t_{1}\right)}$

where $O_{T}$ is the oxygen consumed (referred to $V$, in $\mathrm{mg} \mathrm{l}^{-1}$ ) corresponding to total substrate consumption and $k_{2}$ a constant for a given system of solvent and substrate (in $\mathrm{h}^{-1}$ ). $k_{2}$ is expressed by the following equation based on the Raoult law (Bouchez et al., $1995 \mathrm{c})$ :

$k_{2}=K_{\mathrm{L}}^{\prime} \cdot \mathrm{A}^{\prime} \cdot \frac{M W_{\mathrm{S}}}{m_{\mathrm{S}} \cdot M W_{\mathrm{H}}} \cdot S_{\mathrm{EQ}} \cdot\left(\frac{f_{\mathrm{L}}}{f_{\mathrm{S}}}\right)$

where $K_{\mathrm{L}}^{\prime}\left(\mathrm{dm} \mathrm{h}^{-1}\right)$ is the mass transfer constant for 


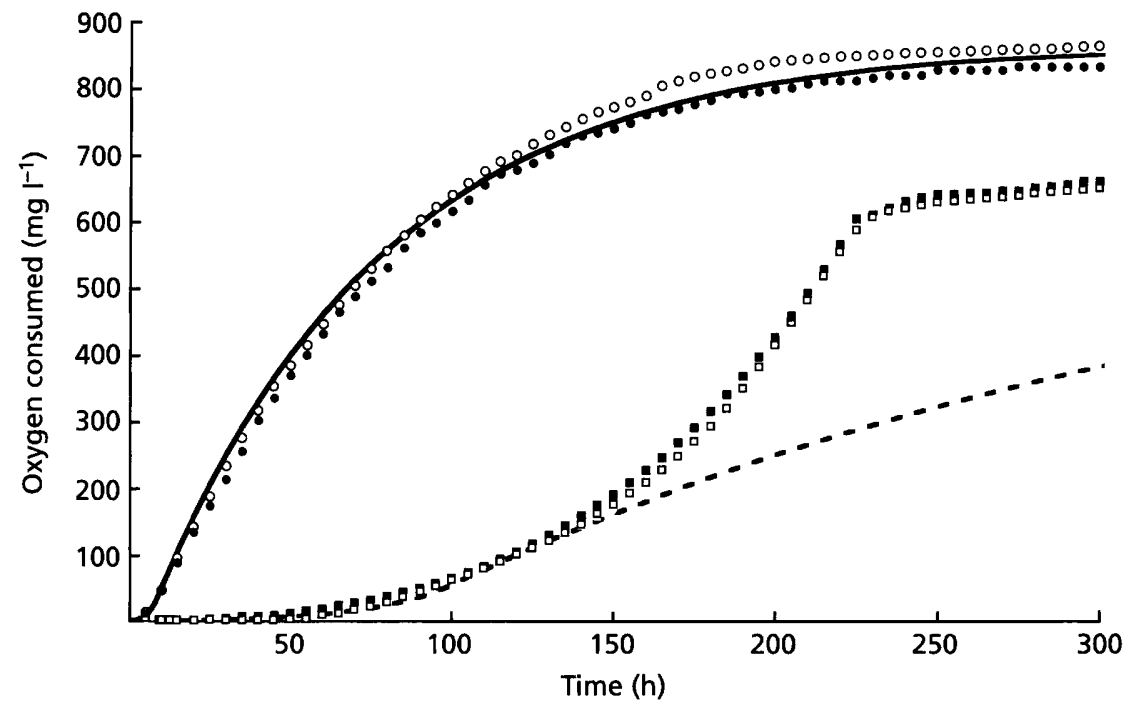

Fig. 1. Experimental biodegradation kinetics of pyrene $\left(S_{0}=370 \mathrm{mg} \mathrm{I}^{-1}\right)$ by strain SFltNa1 $(\square, \square)$ and of phenanthrene $\left(S_{0}=\right.$ $460 \mathrm{mg} \mathrm{l}^{-1}$ ) by strain SPheNa1 $(0,0)$. The lines show the values predicted by the phase-transfer-controlled models for pyrene $(--)$ and phenanthrene (-). Experiments were done in duplicate in the Sapromat apparatus, as described in Methods, with PAH dissolved in HMN $\left(V^{\prime}=0.022 \mathrm{l}\right)$. Values of oxygen consumed $\left(O_{C}\right)$, obtained every $40 \mathrm{~s}$, were summed over periods of $5 \mathrm{~h}$. The curves for transfer-controlled models were calculated from equations (1) and (2) using the values derived from experimental biodegradation data. For pyrene, these values are: $\mu_{\max }=0.04 \mathrm{~h}^{-1}, O_{\mathrm{T}}=660 \mathrm{mg} \mathrm{l}^{-1}$, $O_{\mathrm{C}_{1}}=60 \mathrm{mg} \mathrm{l}^{I^{-1}}$ (from equation 4a), $t_{1}=$ $102 \mathrm{~h}$ (from equation $4 \mathrm{~b}$ ) and $k_{2}=0.004 \mathrm{~h}^{-1}$. $k_{2}$ was calculated according to equation (3) as follows: the value of $K_{\mathrm{L}}^{\prime}$. $A^{\prime}$ was taken as equal to that determined for the system 'phenanthrene solution in $\mathrm{HMN}^{\prime}$ ', i.e. $K_{\mathrm{L}}^{\prime} . A^{\prime}=$ $26.7 \mathrm{I} \mathrm{h}^{-1}$ (Bouchez et al., 1995c); $f_{\mathrm{S}} / f_{\mathrm{L}}$ was obtained from the equation $f_{\mathrm{S}} / f_{\mathrm{L}}=$ $\exp \left[6 \cdot 79 .\left(1-T_{M} / T\right)\right.$ ] (Moretti \& Neufeld, 1989), $T_{M}$ being the melting point of the PAH (in K) by Bjørseth (1983) and $T$ the temperature of the system (in K). For phenanthrene, the corresponding values are: $\mu_{\text {max }}=0.39 \mathrm{~h}^{-1}$, $O_{\mathrm{T}}=800 \mathrm{mg} \mathrm{l}^{-1}, \quad O_{\mathrm{C} 1}=32 \mathrm{mg} \mathrm{l}^{-1}, t_{1}=9.5 \mathrm{~h}$ and $k_{2}=0.014 \mathrm{~h}^{-1}$ (as previously determined by Bouchez et al., 1995c).
PAH transfer (solvent to water), $A^{\prime}$ the contact surface area between solvent and aqueous phases $\left(\mathrm{dm}^{2}\right), M W_{\mathrm{H}}$ and $M W_{\mathrm{S}}$ the molar mass of PAH and of solvent respectively $\left(\mathrm{g} \mathrm{mol}^{-1}\right), m_{\mathrm{S}}$ the mass of solvent (in $\mathrm{mg}$ ), $S_{\mathrm{EQ}}$ the saturating aqueous concentration of $\mathrm{PAH}$ supplied as crystals (in $\mathrm{mg} \mathrm{l}^{-1}$ ), and $f_{\mathrm{L}} / f_{\mathrm{S}}$ the ratio of the $\mathrm{PAH}$ fugacities in the subcooled liquid and solid states.

The values of $\mathrm{O}_{\mathrm{C} 1}$ and $t_{1}$ are given by the following equations:

$O_{\mathrm{C} 1}=\frac{k_{2} \cdot O_{\mathrm{T}}}{\mu_{\max }+k_{2}} \quad$ and $\quad t_{1}=\frac{2 \cdot 3 \cdot \log O_{\mathrm{C} 1}}{\mu_{\max }} \quad(4 \mathrm{a}$ and $4 \mathrm{~b})$

Thus, according to equations (1) and (2), in a model where growth occurs at the expense of the substrate dissolved in the aqueous phase, the constants $\mathrm{O}_{\mathrm{T}}, \mathrm{O}_{\mathrm{C} 1}$, $t_{1}, \mu_{\max }$ and $k_{2}$ allow the kinetics of oxygen consumed during PAH biodegradation to be determined.

The experimental kinetics obtained during the degradation of pyrene dissolved in HMN by strain SFltNa1 are compared with the model presented above in Fig. 1. As discussed below, a first phase of exponential growth was observed, in agreement with the model. Later, however, experimental oxygen consumption was very different and faster than that predicted for growth on the substrate dissolved in the aqueous phase. Indeed, growth following equation (2) should be such that a portion of straight line would be obtained when plotting $\left(O_{T}-O_{C}\right)$ values versus time on a semi-logarithmic scale. How- ever, in our experiments of pyrene biodegradation, such a plot yielded no straight line (the correlation coefficient $r$ was below 0.957). For comparison, the degradation kinetics obtained in previous work for the degradation of phenanthrene dissolved in HMN, by a Pseudomonas sp., are also presented in Fig. 1. In the latter case, the experimental and model kinetics were very close, constituting clear evidence for a biodegradation process implying substrate transfer to the aqueous phase (Bouchez et al., 1995c). Another mechanism of substrate uptake was then considered for the degradation of pyrene.

\section{Model of interfacial kinetics}

Microscopic observation of a culture of strain SFltNa1 growing on pyrene dissolved in HMN showed that bacteria were present in the aqueous phase but also at the surface of the solvent phase (data not shown). A model where growth can occur at the interface of the aqueous and solvent phases was developed. In such a model, as observed microscopically, bacteria are present both in the aqueous phase and at the interface with the solvent phase. Two successive steps of growth take place.

During the first step, at low biomass concentrations, substrate transfer to the aqueous phase allows growth of the bacteria present in the aqueous phase at their maximal specific growth rate. Supposing that the 


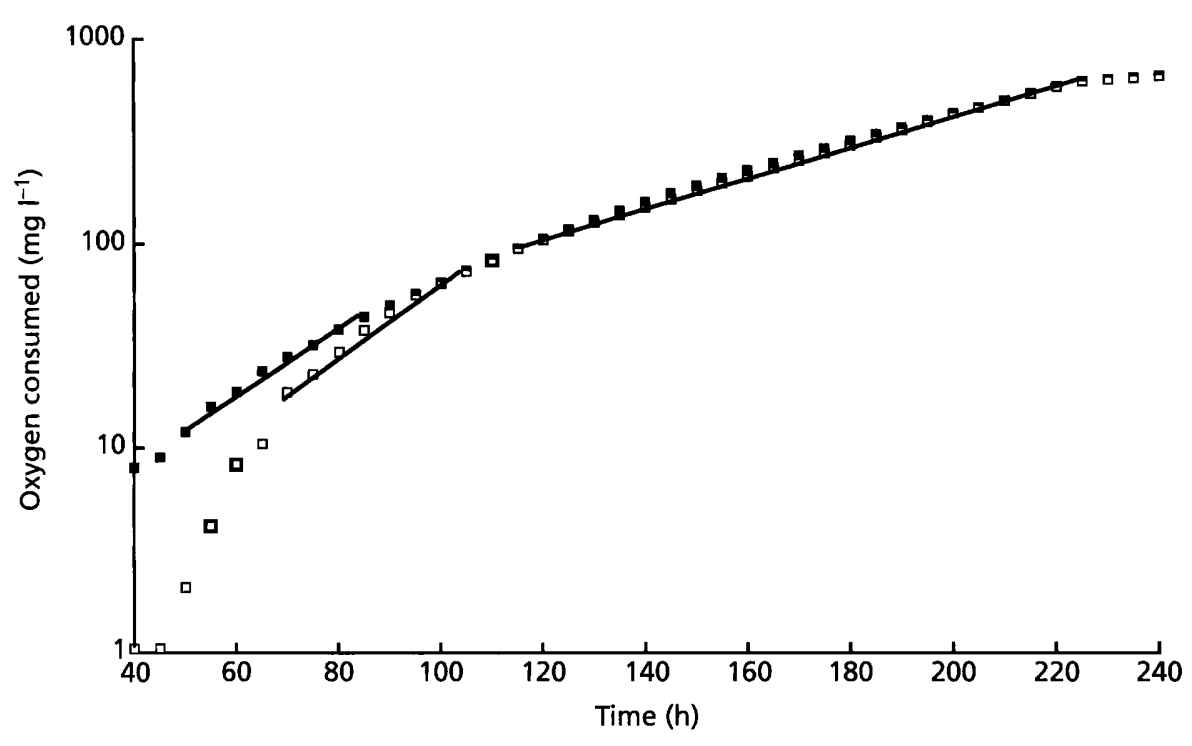

Fig. 2. Determination of the specific growth rates of strain SFItNa1 on pyrene dissolved in $H M N$. The values of oxygen consumed $\left(O_{C}\right)$ for the duplicate experiments presented in Fig. 1 were summed over periods of $5 \mathrm{~h}$ and plotted versus time on a semi-logarithmic scale. bacteria at the interface can also grow at a rate equal to $\mu_{\max }$, the following equation is then verified:

$\frac{\mathrm{d} X}{\mathrm{~d} t}=\mu_{\max } \cdot X_{\mathrm{A}}+\mu_{\max } \cdot X_{\mathrm{S}}=\mu_{\max } \cdot X$

where $X, X_{\mathrm{A}}$ and $X_{\mathrm{S}}$ are the concentrations of total biomass, of biomass in the aqueous phase and of biomass at the interface of the aqueous and solvent phases respectively (referred to $V$, in $\mathrm{mg} \mathrm{l}^{-1}$ ). The oxygen consumed being proportional to the biomass produced, equation (5) becomes:

$\frac{\mathrm{d} O_{\mathrm{C}}}{\mathrm{d} t}=\mu_{\max } \cdot O_{\mathrm{C}}$

Growth following this relationship is exponential, with a growth rate equal to $\mu_{\max }$.

During the second step of growth, because of substrate transfer limitation, growth of the bacteria in the aqueous phase becomes negligible compared to that at the interface of aqueous and solvent phases. Then, the following equation is verified:

$\frac{\mathrm{d} X}{\mathrm{~d} t}=\mu_{\max } \cdot X_{\mathrm{S}}$

When the interfacial surface area between solvent and aqueous phases is not covered (as experimentally observed), a relation taking into account the fact that cell adsorption depends both on the amount of cells in the medium and on interfacial area available can be written according to Dunn (1968). This relation assumes that adsorption and desorption rates of bacteria from the water-solvent surface are fast compared with growth (a likely situation in a well-mixed system) and, accordingly:

$X_{\mathrm{A}}=\frac{a \cdot V}{b \cdot A^{\prime}} \cdot X_{\mathrm{S}}$ where $a$ is the surface area covered per mg of bacteria $\left(\mathrm{dm}^{2} \mathrm{mg}^{-1}\right)$ and $b$ a constant of equilibrium of adsorption/ desorption of bacteria for a hydrophobic surface $\left(1 \mathrm{mg}^{-1}\right)$. So, equation (7) can be rewritten:

$\frac{\mathrm{d} X}{\mathrm{~d} t}=\frac{\mu_{\max } \cdot b \cdot A^{\prime}}{b \cdot A^{\prime}+a \cdot V} \cdot X=\mu_{\mathrm{i}} \cdot X$

and then:

$\frac{\mathrm{d} O_{\mathrm{C}}}{\mathrm{d} t}=\mu_{\mathrm{i}} \cdot O_{\mathrm{C}}$

Thus, the model predicts the existence of an exponential phase: the specific growth rate $\mu_{\mathrm{i}}$ is a constant since it incorporates $a, b$ and $A^{\prime}$, three constants for a given experiment, which are not individually measured.

\section{Comparison of degradation kinetics with the interfacial uptake model}

In order to test the relevance of the interfacial uptake model to the kinetics of pyrene degradation, oxygen consumption values, collected over periods of $5 \mathrm{~h}$, were plotted versus time on a semi-logarithmic scale. As shown in Fig. 2, the data were in excellent agreement with the model of interfacial kinetics. In the duplicate experiments presented, two straight-line portions were obtained. The first portions $(r=0.993$ and $r=0.995$ respectively) corresponded to the first phase of exponential growth (growth at the interface and in the aqueous medium). The slopes yielded growth rates of $0.041 \mathrm{~h}^{-1}$ and $0.039 \mathrm{~h}^{-1}$ respectively, corresponding to the value of $\mu_{\max }$ determined for growth on crystals (Bouchez et al., 1995a). The slopes of the second portions of straight line gave, with excellent correlation coefficients $(r=0.997$ and $r=0.999$ respectively), specific growth rates $\mu_{\mathrm{i}}$ equal, in both cases, to $0.017 \mathrm{~h}^{-1}$. This phase, during which around $80 \%$ of the degradation took place, was likely to correspond to the second phase 


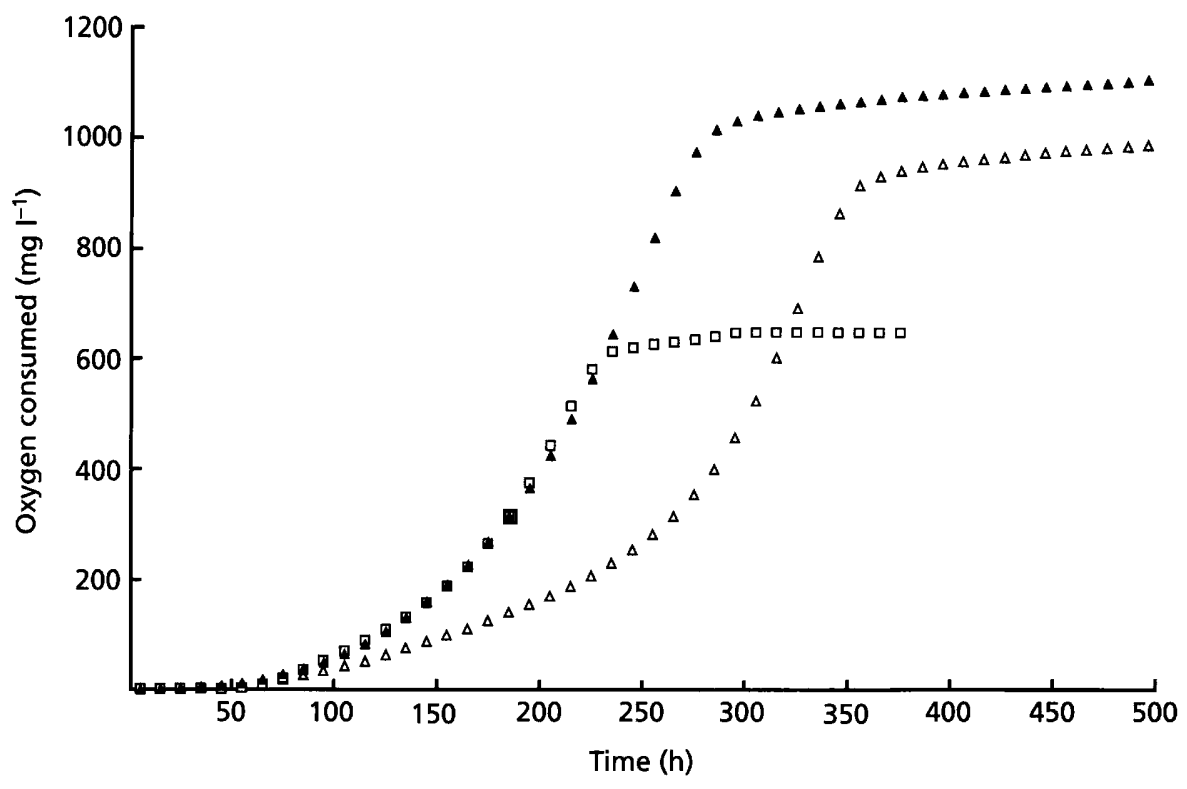

Fig. 3. Influence of the volume of the solvent phase $\left(V^{\prime}\right)$ and of the initial PAH concentration $\left(S_{0}\right)$ on the degradation of pyrene dissolved in HMN by strain SFItNa1. $\triangle, S_{0}=530 \mathrm{mg} \mathrm{l}^{-1}$ and $V^{\prime}=0.022 \mathrm{I} ; \triangle, S_{0}=$ $510 \mathrm{mg} \mathrm{l}^{-1}$ and $V^{\prime}=0.011 \mathrm{l} ; \square, S_{0}=$ $370 \mathrm{mgl}^{-1}$ and $V^{\prime}=0.022 \mathrm{I}$. Experiments were done in the Sapromat apparatus, as described in Methods. Values of oxygen consumed were summed over periods of $10 \mathrm{~h}$.

Table 1. Interfacial specific growth rates for strain SFItNa1 on pyrene dissolved in HMN

Experiments were done in the Sapromat apparatus. $\mu_{\mathrm{i}}$ values were calculated from the slopes of the second portions of straight lines obtained in semi-logarithmic plots of the values of $\mathrm{O}_{\mathrm{C}}$ summed over periods of $5 \mathrm{~h}$.

\begin{tabular}{|c|c|c|c|}
\hline \multicolumn{3}{|c|}{ Experimental conditions } & \multirow{2}{*}{$\begin{array}{c}\mu_{\mathrm{i}} \\
\left(\mathbf{h}^{-1}\right)\end{array}$} \\
\hline$V(1)$ & $V^{\prime}(\mathbf{l})$ & $S_{0}\left(\mathrm{mg} \mathrm{l}^{-1}\right)$ & \\
\hline $0 \cdot 250$ & 0.022 & 370 & 0.017 \\
\hline 0.250 & 0.022 & 530 & 0.017 \\
\hline 0.250 & $0 \cdot 011$ & 510 & 0.011 \\
\hline
\end{tabular}

of exponential growth described by the interfacial kinetics model. As indicated by this method, $\mu_{\mathrm{i}}$ was lower than $\mu_{\max }$.

In the interfacial kinetics model presented, as expressed in equation (9), $\mu_{\mathrm{i}}$ is independent of $S_{0}$ but increases with $A^{\prime}\left(\mathrm{d} \mu_{\mathrm{i}} / \mathrm{d} A^{\prime}>0\right)$ and consequently with the volume of the solvent phase. This fact was verified experimentally by modifying $S_{0}$ and $V^{\prime}$ in experiments of degradation of pyrene dissolved in HMN, by strain SFltNa1. The kinetic data obtained are illustrated in Fig. 3 and compared to those presented before. Kinetics were found to be dependent on $V^{\prime}$ but not on $S_{0}$. As expected, $O_{\mathrm{T}}$ was proportional to $S_{0}$. When the values of $O_{\mathrm{C}}$ were plotted versus time on a semi-logarithmic scale, as previously, all curves showed two straight-line portions (data not shown). The slopes of the first portions gave specific growth rates equal to $\mu_{\max }$. The second straightline portions covered around $80 \%$ of the degradation curves, with excellent correlation coefficients $(r>0.998$ in both cases). The specific growth rates obtained from the slopes of these straight lines are presented in Table 1. $\mu_{\mathrm{i}}$ decreased with $V^{\prime}$ and consequently with $A^{\prime}$, and did not depend on $S_{0}$. This is in agreement with the expression of $\mu_{\mathrm{i}}$ in equation (9). Moreover, the equation system (resulting directly from the expression of $\mu_{\mathrm{i}}$ ):

$$
\left\{\begin{array}{l}
\mu_{1}=\mu_{\max } \cdot \frac{A_{1}^{\prime} \cdot b}{a \cdot V+A_{1}^{\prime} \cdot b} \\
\mu_{2}=\mu_{\max } \cdot \frac{A_{2}^{\prime} \cdot b}{a \cdot V+A_{2}^{\prime} \cdot b}
\end{array}\right.
$$

can be solved only if:

$\frac{A_{2}^{\prime}}{A_{1}^{\prime}}=\frac{\mu_{2} \cdot \mu_{\max }-\mu_{2} \cdot \mu_{1}}{\mu_{1} \cdot \mu_{\max }-\mu_{2} \cdot \mu_{1}}$

In our experimental conditions, having $\mu_{1}=0.017 \mathrm{~h}^{-1}$ and $\mu_{2}=0.011 \mathrm{~h}^{-1}$, it results that $A_{2}^{\prime}=0.57 A_{1}^{\prime}$. This is in agreement with the volumes of solvent introduced $\left(V_{2}^{\prime}=0.5 V_{1}^{\prime}\right)$.

All these results concur in showing that pyrene dissolved in $\mathrm{HMN}$ was consumed by strain SFltNa1 directly at the interface of aqueous and solvent phases and that it could be degraded without prior transfer to the aqueous phase.

\section{Other examples of interfacial growth}

Other experiments on the biodegradation of PAHs, when supplied dissoloved in HMN, were conducted in the Sapromat apparatus: the degradation of pyrene by another Rbodococcus strain, SPyrNa1, and the degradation of fluoranthene by strain SFltNa1. The method described for pyrene degradation by strain SFltNa1 was employed and very similar results were obtained. The degradation kinetics were faster than those allowed by the phase-transfer model. Moreover, when the values of $\mathrm{O}_{\mathrm{C}}$ were plotted on a semi-logarithmic scale as above, after the initial growth phase, straight-line portions 
Table 2. Interfacial growth rates on four-ring PAH dissolved in HMN

Experiments were done in the Sapromat apparatus. $\mu_{\mathrm{i}}$ values were calculated as described in Table 1.

\begin{tabular}{|c|c|c|c|c|c|c|}
\hline \multirow[t]{2}{*}{ Strain } & \multirow[t]{2}{*}{ Substrate } & \multicolumn{3}{|c|}{ Experimental conditions } & \multirow{2}{*}{$\begin{array}{c}\boldsymbol{\mu}_{\mathbf{i}} \\
\left(\mathbf{h}^{-1}\right)\end{array}$} & \multirow{2}{*}{$\begin{array}{c}\boldsymbol{\mu}_{\max } \\
\left(\mathbf{h}^{-1}\right)\end{array}$} \\
\hline & & $V(1)$ & $V^{\prime}(1)$ & $\begin{array}{c}S_{0} \\
\left(\mathrm{mg} \mathrm{l}^{-1}\right)\end{array}$ & & \\
\hline SPyrNa1 & Pyrene & $0 \cdot 250$ & $0 \cdot 022$ & 370 & $0 \cdot 015$ & ND \\
\hline SFltNa1 & Fluoranthene & $0 \cdot 250$ & 0.022 & 415 & $0 \cdot 019$ & $0.025^{*}$ \\
\hline
\end{tabular}

ND, Not determined.

$* \mu_{\max }$ value obtained on crystals.

were obtained covering more than $50 \%$ of the degradation curves $(r>0.998)$ (data not shown). As shown in Table 2, the values of $\mu_{\mathrm{i}}$ deduced from the slopes of these straight lines were lower than the measured values of $\mu_{\max }$, obtained with crystals.

These results are in agreement with the involvement of an interfacial uptake mechanism in the degradation of pyrene dissolved in $\mathrm{HMN}$, by strain SPyrNa1, and in the degradation of fluoranthene dissolved in $\mathrm{HMN}$, by strain SFltNa1.

\section{DISCUSSION}

We have demonstrated here that the growth kinetics of Rhodococcus SFltNa1 on pyrene dissolved in HMN were faster than those allowed by physicochemical transfer of the PAH from the solvent to the aqueous phase. The results fitted well with a model where the PAH was consumed both directly from the solvent phase and, after solubilization, from the aqueous phase. In these conditions, mixed growth took place at low cell densities and strictly interfacial uptake predominated later on. However, strictly interfacial uptake should occur only when high interfacial cell densities and low substrate transfer rates to the aqueous phase make negligible the contribution of bacterial growth in the aqueous phase. It is actually somewhat surprising to observe the early appearance of the strictly interfacial growth phase. However, the independence of the growth rate on substrate concentrations in the solvent phase constitutes determinant evidence for a mechanism of interfacial uptake. Indeed, as noted by Westgate et al. (1995), the degradation rates in both interfacial uptake and mass-transfer mechanisms are dependent on the volumes of the solvent phase. However, the degradation rates are dependent on substrate concentrations only in the mass-transfer mechanism.

An interfacial mechanism of substrate uptake implies strong interactions between the bacteria and the solvent phase. In our cultures growing on PAHs dissolved in HMN, we sometimes observed long lag phases (two or three weeks) which did not occur in cultures on pyrene supplied as crystals or in controls (growth on acetate in the presence of $\mathrm{HMN}$ ). A possibility is that PAH could be more toxic to the bacteria during direct contact in the solvent phase than when supplied at low concentrations via an aqueous phase. In these conditions, interfacial growth would begin after a period of adaptation.

From a general point of view, two modes of PAH uptake by degradative bacteria have now been recognized: uptake of the substrate dissolved in the aqueous phase and interfacial uptake. The first mode has been proposed by various authors for the degradation of naphthalene and phenanthrene (Stucki \& Alexander, 1987; Volkering et al., 1992; Wodzinski \& Bertolini, 1972; Wodzinski \& Coyle, 1974) and demonstrated with Pseudomonas SPheNa1 in the degradation of phenanthrene (Bouchez et al., 1995c). In the second mode, interfacial growth predominated, as illustrated in this work, without excluding the utilization of the substrate dissolved in the aqueous medium. The possibility of interfacial uptake in $\mathrm{PAH}$ degradation has been discussed by Ortega-Calvo \& Alexander (1994) and Wodzinski \& Larocca (1977). However, to our knowledge, this is the first time that definite evidence for such a mechanism has been presented for this type of compound. The occurrence of interfacial uptake is of considerable significance for PAH biodegradation. In particular, it dispels theoretical objections to the possibility of significant degradation of five- and six-ring PAHs on the grounds of their solubility being too low.

It is worth noting that the involvement of biosurfactants, the third mechanism proposed for the uptake of alkanes (Goswami \& Singh, 1991; Haferburg et al., 1986; Hommel, 1994; Nakahara et al., 1977), was not observed in either case of PAH uptake examined by us. In pyrene degradation, the production of biosurfactants as a possible cause for increasing biodegradation rates (by increasing interfacial surface area) was a point to consider. However, glycolipid production by strain SFltNa1 grown on various carbon sources, including hexadecane, a quite insoluble compound, was not observed (data not shown). In addition, production of biosurfactants cannot easily explain the strictly exponential growth rate, and its characteristics, observed in the experiments presented here. Involvement of biosurfactants in other cases of PAH biodegradation remains plausible, although reports of biosurfactant production 
by bacteria grown on $\mathrm{PAH}$ are, at present, rare (Aitken et al., 1995; Déziel et al., 1996).

In fact, the mode of PAH uptake should be dependent not only on the solubility of the substrate but also on the bacteria and on the hydrophobicity of their cell envelope, which determines their capacity to adhere to the hydrocarbon phase. From this point of view, it is interesting to note the lipophilic character imparted by the presence of mycolic acids to the cell envelope of rhodococci and other members of the family Nocardiaceae (Goodfellow, 1992). Also worth mentioning is the fact that the PAH-degrading Rhodococcus strains we isolated, including SFltNa1, commonly grew on hexadecane (Bouchez et al., 1995a), a carbon source quite likely to be degraded via an interfacial mechanism.

\section{ACKNOWLEDGEMENTS}

We thank S. Arino for performing and interpreting the glycolipid production tests. We also acknowledge stimulating discussions with J.-Y. Leveau, B. Besnainou, A. Maurel and M.-F. Libert.

\section{REFERENCES}

Aitken, M. D., Grimberg, S. J., Nagel, J., Nagel, R. D. \& Stringfellow, W. T. (1995). The role of biosurfactants in biodegradation of hydrophobic pollutants by indigenous microorganisms in soil. NTIS Report PB96-118609.

Bjørseth, A. (ed) (1983). Handbook of Polycyclic Aromatic Hydrocarbons, pp. 709-718. New York: Marcel Dekker.

Bouchez, M. (1995). La biodégradation des hydrocarbures aromatiques polycycliques: métabolisme de substrats non conventionnels. Doctorate thesis, Ecole National des Industries Agroalimentaires, Massy, France.

Bouchez, M., Blanchet, D., Besnainou, B. \& Vandecasteele, J.-P. (1995a). Diversity of metabolic capacities among strains degrading polycyclic aromatic hydrocarbons. In Microbial Processes for Bioremediation, vol. 8, pp. 153-159. Edited by R. E. Hinchee, C. M. Vogel \& F. J. Broockman. Columbus: Battelle Press.

Bouchez, M., Blanchet, D. \& Vandecasteele, J.-P. (1995b). Degradation of polycyclic aromatic hydrocarbons by pure strains and by defined strain associations: inhibition phenomena and cometabolism. Appl Microbiol Biotechnol 43, 156-164.

Bouchez, M., Blanchet, D. \& Vandecasteele, J.-P. (1995c). Substrate availability in phenanthrene biodegradation: transfer mechanism and influence on metabolism. Appl Microbiol Biotechnol 43, 952-960.

Cerniglia, C. E. (1992). Biodegradation of polycyclic aromatic hydrocarbons. Biodegradation 3, 351-368.

Cerniglia, C. E. (1993). Biodegradation of polycyclic aromatic hydrocarbons. Curr Opin Biotechnol 4, 331-338.

Davies, J. L. \& Evans, W. C. (1964). Oxidative metabolism of naphthalene by soil pseudomonads. Biochem J 91, 251-261.

Déziel, E., Paquette, G., Villemur, R., Lépine, F. \& Bisaillon, J.-G. (1996). Biosurfactant production by a soil Pseudomonas strain growing on polycyclic aromatic hydrocarbons. Appl Environ Microbiol 62, 1908-1912.

Dunn, I. J. (1968). An interfacial kinetics model for hydrocarbon oxidation. Biotechnol Bioeng 10, 891-894.

Goodfellow, M. (1992). The family Nocardiaceae. In The Prokaryotes, 2nd edn, vol. 2, pp. 1188-1213. Edited by A. Balows, H. G. Trüper, M. Dworkin, W. Harder \& K.-H. Schleifer. New York \& Berlin: Springer.

Goswami, P. \& Singh, H. D. (1991). Different modes of hydrocarbon uptake by two Pseudomonas species. Biotechnol Bioeng 37, 1-11.

Haferburg, D., Hommel, R., Claus, R. \& Kleber, H.-P. (1986). Extracellular microbial lipids as biosurfactants. Adv Biochem Eng Biotechnol 33, 53-93.

Hommel, R. K. (1994). Formation and function of biosurfactants for degradation of water-insoluble substrates. In Biochemistry of Microbial Biodegradation, pp. 63-87. Edited by C. Ratledge. Dordrecht: Kluwer.

Luthy, R. G., Dzombak, D. A., Peters, C. A., Roy, S. B., Ramaswami, A., Nakles, D. V. \& Nott, B. R. (1994). Remediating tar-contaminated soils at manufactured gas plant sites. Environ Sci Technol 28, 266A-276A.

May, W. E., Wasik, S. P. \& Freeman, D. H. (1978). Determination of the solubility behavior of some polycyclic aromatic hydrocarbons in water. Anal Chem 50, 997-1000.

Moretti, C. J. \& Neufeld, R. D. (1989). PAH partitioning mechanisms with activated sludge. Wat Res 23, 93-102.

Nakahara, T., Erickson, L. E. \& Gutierrez, J. R. (1977). Characteristics of hydrocarbon uptake in cultures with two liquid phases. Biotechnol Bioeng 19, 9-25.

Ortega-Calvo, J.-J. \& Alexander, M. (1994). Role of bacterial attachment and spontaneous partitioning in the biodegradation of naphthalene initially present in nonaqueous-phase liquids. Appl Environ Microbiol 60, 2643-2646.

Stucki, G. \& Alexander, M. (1987). Role of dissolution rate and solubility in biodegradation of aromatic compounds. Appl Environ Microbiol 53, 292-297.

Volkering, F., Breure, A. M., Sterkenburg, A. \& van Andel, J. G. (1992). Microbial degradation of polycyclic aromatic hydrocarbons: effect of substrate availability on bacterial growth kinetics. Appl Microbiol Biotechnol 36, 548-552.

Westgate, S., Bell, G. \& Halling, P. J. (1995). Kinetics of uptake of organic liquid substrates by microbial cells: a method to distinguish interfacial contact and mass-transfer mechanisms. Biotechnol Lett 17, 1013-1018.

Wilson, S. C. \& Jones, K. C. (1993). Bioremediation of soil contaminated with polynuclear aromatic hydrocarbons (PAHs): a review. Environ Pollut 81, 229-249.

Wodzinski, R. S. \& Bertolini, D. (1972). Physical state in which naphthalene and bibenzyl are utilized by bacteria. Appl Microbiol 23, 1077-1081.

Wodzinski, R. S. \& Coyle, J. E. (1974). Physical state of phenanthrene for utilization by bacteria. Appl Microbiol 27, 1081-1084.

Wodzinski, R. S. \& Larocca, D. (1977). Bacterial growth kinetics on diphenylmethane and naphthalene-heptamethylnonane mixtures. Appl Environ Microbiol 33, 660-665.

Received 24 June 1996; revised 30 October 1996; accepted 5 December 1996. 